\title{
A Declaração dos Direitos da Criança de 1924, a Liga das Nações, o modelo tutelar e o movimento Save the children: o nascimento do menorismo ${ }^{\diamond}$
}

\section{The 1924 Declaration of the Rights of the Child, the League of the Nations, the tutelary model and the Save the children movement: the origin of minorism}

Maria Nilvane Fernandes* Ricardo Peres da Costa**

Resumo: O nascimento do menorismo é problematizado neste artigo, que se orienta por uma pesquisa histórica e documental. Esta análise objetiva conceituar o tema e apresentar uma linha de compreensão sobre o nascimento e a consolidação do modelo tutelar que teve início nos Estado Unidos e de lá se disseminou para a Europa e América Latina. Como movimento possui os seguintes marcos históricos: a) os Congressos Internacionais das Prisões; b) a Lei das Cortes Juvenis, que culminou com a efetivação do primeiro tribunal de menores, em 1899; c) o movimento reformista Child Savers/Salvadores da Infância; e, d) a Declaração dos Direitos da Criança (1924). O artigo conclui que o menorismo foi uma política de contenção dos filhos da classe trabalhadora, que articulou a separação de adultos e menores na execução da pena, eliminando formalidades judiciais com vistas a tutelar os menores, diferenciando, para tanto, instituições de correção e de reforma, e eliminando a distinção entre infração e abandono, no âmbito da Justiça. Como base teórica possui alicerce na Psicologia do Desenvolvimento de Stanley Hall. Juridicamente, a proposta se consolidou, no final do século XIX, quando retirou o pátrio poder das famílias consideradas inadequadas para educar seus filhos.

\footnotetext{
$\checkmark \quad$ Este artigo contou com o apoio financeiro da Fundação de Amparo à Pesquisa do Estado do Amazonas (FAPEAM), da Universidade Federal do Amazonas (UFAM) e da Coordenação de Aperfeiçoamento de Pessoal de Nível Superior (CAPES).

Professora Permanente do Programa de Pós-Graduação da Universidade Federal do Amazonas (UFAM). Mestra e Doutora em Educação (UEM). Mestra em Adolescente em Conflito com a Lei (UNIBAN/SP); Doutorado Sanduíche no Instituto de Educação da Universidade de Lisboa/Portugal (2017). Líder do Grupo de Estudos, Pesquisa e Extensão sobre Políticas, Educação, Violências e Instituições (GEPPEvi). E-mail: nilvane@gmail.com. ORCID: http://orcid.org/oooo-0002-3420-2714.

*** Doutor e Mestre em Serviço Social e Política Social (UEL). Especialista em Educação, Pobreza e Desigualdade Social (UFPR). Graduado em Filosofia e Gestão da Segurança Pública. Pesquisador com ênfase no trabalho do Agente de Segurança Socioeducativo. Consultor, autor de artigos e organizador de livros na área do Sistema de Justiça Juvenil. E-mail: peresrpc@gmail.com Orcid: https://orcid.org/oooo-0o01-9563-5751
} 
Palavras-chave: Menorismo. Modelo Tutelar. Declaração dos Direitos da Criança.

Abstract: The origin of minorism is discussed in this article, which is guided by historical and documentary research. This analysis aims to conceptualize the issue and present a line of comprehension about the origin and consolidation of the tutelary model, which began in the United States and spread from there to Europe and Latin America. As a movement, it has the following historical landmarks: a) International Prison Congresses; b) the Youth Courts Law, which culminated in the establishment of the first juvenile court in 1899; c) the reformist movement Child Savers; and, d) the Declaration of the Rights of the Child (1924). The article concludes that the minorism was a policy of containment for the children of the working class, which articulated the separation of adults and minors in the enforcement of the sentence and eliminating judicial formalities to protect minors. Therefore, these events differentiated correctional and pension institutions, eliminating the distinction between infraction and abandonment, within the scope of justice. As a theoretical basis, it has a foundation in Stanley Hall's Developmental Psychology. Legally, at the end of the 19th century, the proposal was consolidated when it removed the paternal power from families considered inadequate to educate their children.

Keywords: Minorism. Tutelary Model. Declaration of the Rights of the Child.

\section{Introdução}

No decorrer do século XX, as conquistas políticas se acentuaram com a promulgação de várias normativas no âmbito dos direitos sociais e políticos. A área da infância seguiu esse movimento, que esteve articulado com um projeto de sociedade construído séculos antes. O Congresso Internacional das Prisões foi um movimento proposto pelos EUA com o objetivo de reformar o sistema prisional e realizar a separação de adultos e menores no cumprimento da pena. Essa reforma possuía como referência a criação de duas leis, publicadas em 1874 e 1892 nos EUA, e que determinavam que os menores acusados de delitos fossem julgados de maneira separada dos adultos. 
Nesse sentido, o artigo se baseia em uma pesquisa histórica para apresentar o contexto de nascimento das instituições de privação de liberdade para menores e, consequentemente, evidencia os motivos que contribuíram para a criação do menorismo. Em momento posterior, desvela o contexto histórico que contribuiu para a criação da Organização Internacional Não Governamental (OING) Save the Children como instituição de defesa dos direitos da criança, que é reconhecida por ter escrito a Declaração dos Direitos da Criança de 1924 ou Carta de Genebra contribuindo, efetivamente, para a disseminação do modelo tutelar.

Na América Latina, os estudiosos costumam identificar que o modelo menorista foi implantada com a Lei Agote, de 1919, na Argentina. Entretanto, como demonstraremos no corpo do artigo, em 1875 e 1890, o termo e os princípios já eram evidenciados nos decretos que regulamentavam o Asilo de Meninos Desvalidos.

A estruturação de um modelo jurídico sobre a penalização da infância divide-se em três fases: Modelo Penal Indiferenciado, Modelo Tutelar e Modelo Penal Juvenil. A primeira fase, denominada Modelo Penal Indiferenciado, foi iniciada no século XVIII e se manteve até o início do século XIX. Nessa fase, os menores de idade eram atendidos da mesma forma que os adultos, com exceção para os que possuíam menos de sete anos de idade "[...] que se consideravam, tal como na velha tradição do direito romano, absolutamente incapazes e cujos atos eram equiparados aos dos animais" (MÉNDEZ, 2006, p. 1). Se possuíssem entre sete e dezoito anos eram julgados pelo modelo retribucionista, ou seja, recebiam uma redução da pena em um terço. O contexto atual caracteriza-se como sendo a terceira fase, denominada por estudiosos como um Modelo Penal Juvenil que, em nosso entendimento, está num processo de transição, ainda não consolidado. Nesse artigo, analisaremos o período inicial da constituição do Modelo Tutelar e a sua influência no contexto atual.

A fase do Modelo Tutelar, objeto desta análise, relaciona-se com a conquista de uma autonomia normativa e científica do Direito Penal em relação aos demais ramos do Direito, o que contribuiu para produzir uma racionalização da pena e uma reflexão sobre as suas finalidades. Foi nesse período que ocorreu a definitiva separação entre mulheres, homens e menores de idade no cumprimento da pena. Beccaria (2000) foi o primeiro representante do Direito a 
defender, em 1764, a igualdade perante a lei dos criminosos que cometessem o mesmo delito.

A racionalização da pena encontrava-se em acordo com o movimento filosófico e científico da humanidade que, atrelado ao liberalismo, vivenciava, politicamente, a ascensão da burguesia e a limitação dos poderes absolutos do Estado. No século XIX, esse movimento se atrelou ao positivismo, já que o direito positivo é aquele que tem por princípio a vontade dos legisladores. Em última análise, é produto do Estado: portanto, posterior ao contrato social que consiste em um conjunto de normas gerais, emanadas da vontade do legislador e suscetíveis de exteriorização, cujo cumprimento só pode ser garantido se for emanada uma força intencional do aparelho do Estado (ZANELLA, 2014).

Se, até o século XVIII, a Europa era o centro do pensamento e da produção teórica e prática sobre formas de punir o criminoso, a partir do século XIX houve uma inversão e o movimento internacional das prisões passou a ser proposto seguindo os modelos implementados nos Estados Unidos da América (EUA). O marco inicial desse movimento esteve atrelado aos modelos prisionais estruturados naquele país e, a sua influência, na organização de um movimento que pretendeu unificar a forma de punir o preso. Esse modo atingiu também a infância e influenciou tanto a Europa, quanto a América Latina.

\section{A constituição do modelo tutelar}

Depois que o termo delinquente juvenil foi cunhado nos Estados Unidos em 1810, a cidade de Nova Iorque, em 1824, promulgou a primeira lei sobre o tema e definiu o perfil dos tais delinquentes juvenis estabelecendo que eles possuíam, necessariamente, menos de 21 anos de idade (SAVAGE, 2009). Em meados do século XIX, teve início o diálogo entre os Estados Unidos, o Reino Unido e o norte da Europa sobre o problema juvenil. Decorrente desse movimento, um grupo de empresários criou o primeiro New York Youth Asylum/Asilo da Mocidade de Nova York para crianças com idade entre sete e quinze anos de idade. No mesmo período, duas décadas antes do primeiro livro L'uomo delinquente/O homem delinquente, de Césare Lombroso (2001), Mary 
Carpenter ${ }^{1}$, na Inglaterra, publicou os livros Reformatory Schools for the children of the perishing and dangerous classes and for juvenile offenders/Escolas reformatórias para crianças pertencentes às classes perigosas e para infratores juvenis (1851) e Juvenile delinquents: their condition and treatment/Delinquentes juvenis: suas particularidades e tratamentos (1853).

Concomitante a isso, nos EUA eram realizados congressos internos para discutir e alinhar os procedimentos prisionais. Com o objetivo de propor um alinhamento internacional, o Presidente Ulysses Simpson Grant nomeou, em 1871, um comissário para visitar diversos países europeus a fim de selecionar membros que deveriam compor um comitê para organizar um Congresso Internacional das Prisões (CIP), nos moldes daqueles realizados internamente.

Londres foi a cidade escolhida para sediar o primeiro evento. Assim, em 1872, o Congresso reuniu agentes penitenciários, reformadores sociais e especialistas de 22 países, dentre eles, EUA, México, Brasil, Chile, Inglaterra e todas as nações europeias, com exceção de Portugal (CIP, 1872). Ao final, formouse um comitê que passou a se reunir, periodicamente, com o objetivo de recolher estatísticas penitenciárias, incentivando, assim, uma reforma penal. Desse movimento nasceu a separação de adultos e jovens no sistema prisional.

Os estabelecimentos apropriados para jovens reclusos são, para além de todas as contradições, o ponto principal dos sistemas penitenciários. Para reformar as massas criminais, é com a infância que devemos começar [...]; Esquecemo-nos, muitas vezes, de que estas crianças são insubordinadas e pervertidas e que, em um período posterior, irão formar as gerações de transgressores adultos, cujos crimes perturbarão e aterrorizarão a sociedade. Parece-me que há um grande grupo de reformatórios ou prisões juvenis para jovens e adultos que necessitam de reformas, pois estão muito antigas [...]. Uma instituição deste tipo, chamado de reformatório industrial, está agora em processo de construção em Elmira, Nova York. Esta experiência é da mais alta importância para a ciência penitenciária, e seu progresso será observado com vivo interesse pelos amigos de reforma do sistema

$1 \quad$ Carpenter (1807-1877) foi uma reformadora educacional e social inglesa. Como filha de religioso, fundou uma escola para dar oportunidades educacionais anteriormente indisponíveis para crianças pobres e jovens infratores em Bristol. Dessa experiência, publicou artigos e livros e realizou um lobbying que foi fundamental na elaboração de várias leis em meados do século XIX. Respeitada, dentre outras coisas, por ter sido a primeira mulher a ter um artigo publicado pela Statistical Society of London/Sociedade Estatística de Londres. 
prisional neste e em outros países ${ }^{2}$ (CIP, 1872, p. 278, grifo nosso, tradução do original).

O Reformatório Elmira para rapazes não condenados, mencionado na mensagem, foi inaugurado dois anos depois. A partir de então, os EUA começaram a colocar em prática um modelo militar de atendimento nessa instituição, com ampla intervenção psicológica de incentivos para a autodisciplina. Elmira recebia rapazes ainda não condenados para ensinar-lhes leitura, caligrafia, ditado, noções de aritmética, princípios de direito internacional e de economia política, bem como, história geografia. Para tanto, mantinha-os internados e atuava com objetivos de reabilitação, utilizando uma disciplina rigorosa, alinhada ao treinamento militar.

O Reformatório diferenciava-se das demais prisões da época porque buscava reformar os jovens usando métodos psicológicos, em vez de físicos, com sentenças indeterminadas, das quais eles só eram liberados após a determinação do diretor, de que haviam pago sua dívida com a sociedade; isto, apesar de, inicialmente, serem jovens não infratores. Para reformar e reabilitar, havia um sistema de incentivos para a autodisciplina. Sob a influência do modelo Crofton 3 e de outros experimentos australianos, a disciplina era militarizada com uniformes e marchas. Esse reformatório influenciou a construção de 25 outros, em 12 estados do país e atingiu seu auge em 1910 (CIP, 1900; VAZ, 1905).

Quatro anos depois da criação do Reformatório Elmira, o segundo Congresso Internacional das Prisões (CIP) foi sediado em Estocolmo, na Suécia, que, não coincidentemente, apesentou no relatório o debate sobre o seguinte problema:

\footnotetext{
2 Establishments appropriated to young prisoners are, beyond all contradiction, the leading point in every penitentiary system. To reform the criminal masses, it is with childhood that we must commence; [...]. We too often forget that it is these insubordinate and perverted children who, at a later period, will form the generations of adult transgressors whose crimes will disturb and terrify society. It seems to me that there is great need of a class of reformatories or juvenile prisons for boys and young men too old for the ordinary reformatory, [...]. An institution of this kind, called an industrial reformatory, is now in process of construction at Elmira, New York. This experiment of the highest importance to penitentiary science, and its progress will be watched with a lively interest by the friends of prison reform in this and other countries.

3 "O Crofton se baseava pela mistura do rigor do modelo pensilvânico com o modelo alburniano. Quando o preso chegava à instituição prisional, ficava isolado na cela - modelo pensilvânico. Passado o período de adaptação, realizava trabalhos em comum com outros prisioneiros durante o dia e permanecia isolado durante a noite - modelo alburniano. Este modelo fundou uma terceira etapa da prisão, em que o preso que provasse bom comportamento e bom aproveitamento nas oficinas seria transferido para uma prisão rural. O sistema Crofton inaugurou o regime de progressão da pena, que passou da excessiva rigidez ao abrandamento, à medida que o prisioneiro demonstrasse sua recuperação" (ZANELLA, 2018, p. 110).
} 
Quais princípios devem ser seguidos na organização de estabelecimentos para jovens absolvidos por terem agido sem discernimento e mantidos à disposição do governo durante um período especificado por lei? De acordo com quais princípios é apropriado organizar instituições para vagabundos, mendigos, crianças abandonadas etc.?4 (CIP, 1879, p. XIII, grifo nosso, tradução do original).

Conforme evidencia o relatório, os especialistas percebiam que deveria haver um tratamento diferenciado entre aqueles que haviam cometido um crime sem discernimento e os que eram vagabundos, mendigos e abandonados, mas que não haviam praticado um ato criminoso, ainda que os dois grupos permanecessem sob a tutela do governo, presos, como no caso daqueles que estavam inseridos no Reformatório Elmira.

Decorrente desse debate, o Congresso de 1878 estabeleceu uma distinção entre os reformatórios e as colônias correcionais. Assim, enquanto os reformatórios buscavam punir os que já haviam sido condenados por terem cometido um crime, as colônias correcionais eram destinadas à prevenção ou à correção dos vagabundos, mendigos e abandonados, pelo trabalho. Naquele contexto, não houve debates sobre as medidas a serem tomadas em relação àqueles que haviam cometido o ato com discernimento, visto que a intenção era a mesma: institucionalizar a todos.

Em um contexto no qual o movimento de trabalhadores ganhava ênfase em vários países, dentre eles, os EUA, a exploração massiva das classes populares e a existência de crianças pauperizadas nas fábricas inflava a luta dos sindicatos (MARKEL, 2009). A participação efetiva, não apenas dos trabalhadores adultos, mas também dos pequenos trabalhadores, era uma preocupação, em um período que os filhos dessa classe participavam dos sindicatos, ativamente. Portanto, era necessário educar os homens do futuro para a defesa do capitalismo, ideia que foi desenvolvida pelo positivista Émile Durkheim (DURKHEIM, 2011).

Assim, quando em 1886, o movimento sindical de Chicago, Estado de Illinois, nos EUA, entrou em conflito com a polícia durante a realização de um comício, em um evento de grandes proporções, sobrou para a classe trabalhadora

$4 \quad$ D'après quels principes convient-il d'organiser les établissements affectés aux jeunes gens acquittés comme ayant agi sans discernement et mis à la disposition du gouvernement pendant la durée déterminée par la loi? D'après quels principes convient-il d'organiser les institutions affectées aux enfants vagabonds, mendiants, abandonnés etc.? 
a comemoração do $10^{\circ}$ de maio e, para os filhos dos trabalhadores, a criação da Juvenile Court Act/Lei das Cortes Juvenis.

A intervenção na população jovem pobre e imigrante culminou com a promulgação de uma lei que criou as primeiras cortes juvenis promovendo, dentre outras coisas, a separação de adultos e menores nas prisões. A justificativa ideológica para prender indiscriminadamente os filhos dos trabalhadores foi um movimento que, na nossa análise, constitui um marco histórico que dá início ao denominado modelo tutelar menorista que, por sua vez, influencia a criação de um amplo movimento capitaneado por reformadores que passaram a defender a criação de tribunais de justiça para menores e a separação de adultos e menores nas prisões, por meio de um discurso humanitário e de piedade institucional.

O movimento de salvação das crianças não foi um empreendimento humanitário em prol da classe trabalhadora e contra a ordem estabelecida. Em vez disso, o impulso veio principalmente da classe média e alta que contribuiu para a invenção de novas formas de controle social para proteger o seu poder e privilégios ${ }^{5}$ (PLATT, 1997, p. 21, traduzido do original).

O empenho nessa autopreservação contribuiu, inclusive, para que os grandes industriais aceitassem a proibição do trabalho infantil, em um contexto em que as pequenas mãos não eram mais tão necessárias, considerando-se o processo de reestruturação produtiva taylorista que estava em pleno desenvolvimento.

Platt (1997), no livro The Child Savers: the Invention of Delinquency/Os salvadores da infância: a invenção da delinquência, evidenciou que, apesar de tais salvadores promoverem um discurso humanitário, o movimento decorreu da crescente preocupação em se manter a ordem e o controle social dos menores, mantendo-os longes de possíveis influências anarquistas. Portanto, o grupo de pessoas que se denominava Child Savers/Salvadores da Infância constituiu um movimento contrarrevolucionário que estava subsidiado por dois pontos principais: o aumento da idade da responsabilização penal ${ }^{6}$ e a imposição de

$5 \quad$ El movimiento pro salvación del niño no era una empresa humanitaria en ayuda de la clase obrera y frente al orden establecido. Al contrario, su impulso procedía primordialmente de la clase media y la superior, que contribuyeron a la invención de nuevs formas de control social para proteger su poderío y sus privilegios.

6 A influência do modelo tutelar que tem como fundamento o menorismo, na ampliação da Idade Penal, será discutida no artigo intitulado $O$ menorismo, o modelo tutelar e o aumento da maioridade penal na América Latina no início do século XX (no prelo). 
Revista Brasileira de História \& Ciências Sociais - RBHCS

Vol. 13 No 25, Edição Especial de 2021

sanções específicas diferenciadas dos adultos aos chamados delinquentes (PLATT, 1997).

Como sabemos, desde o século anterior, os menores abandonados já eram mencionados nas leis dos países e atendidos em instituições criadas para esse fim. Nesse aspecto, o aumento da idade de responsabilização penal tinha como objetivo principal retirar os menores de idade das instituições penitenciárias para adultos, tendo em vista as "[...] deploráveis condições de encarceramento e a promiscuidade entre menores e adultos [que] geraram com maior ou menor intensidade em todo o continente forte indignação moral [...]” (MÉNDEZ, 1998, p. 21).

As reformas, longe de serem motivadas pela preocupação com a desigualdade social que promovia, em maior ou menor intensidade o abandono material ou psicológico dos delinquentes, visavam o asseio moral e o controle social. Assim, a salvaguarda da integridade das crianças estava "[...] subordinada ao objetivo de proteção da sociedade diante de futuros delinquentes" (grifo do autor, MÉNDEZ, 1998, p. 51) ou, ainda, de possíveis adeptos de movimentos de trabalhadores.

Tal movimento, mesmo que tivesse contado com a participação ativa da classe média, de profissionais de várias áreas e de instituições filantrópicas necessitou, preponderantemente, dos mais ricos, mulheres e damas da sociedade, que se dispuseram a lutar pela moralidade dos menores. A moral da causa trouxe para o grupo de reformadores, os religiosos, os herdeiros de grandes fortunas e as damas pertencentes à classe mais abastada da sociedade.

As esposas dos detentores de instituições bancárias e de vastas extensões de terras e propriedades tornaram-se as mais ardentes defensoras da salvação da infância e, nessa defesa, os religiosos incorporaram os trabalhadores sociais na sua rotina. A medicina deu sua contribuição para o novo sistema penal, para os reformatórios e escolas correcionais para a infância. Os juristas contribuíram com a experiência técnica na redação e orientação para o cumprimento das novas leis e os acadêmicos descobriram um novo mercado de trabalho, de publicações e conferências.

Nota-se que os salvadores da infância eram formados, em sua maioria, pelos verdadeiramente interessados em aliviar a miséria humana e melhorar a vida dos pobres mas, de igual modo, por uma pequena parte detentora do poder 
econômico e político que desejava garantir que qualquer possibilidade de alternativa socialista fosse rechaçada, inclusive, atuando fortemente para a proibição do trabalho infantil. De um lado, a reforma combinava um caráter progressista enquanto fenômeno, mas tinha, por outro, uma vertente ideológica reacionária.

Era, também, um movimento romântico, que legitimava novas carreiras para as mulheres cultas em um trabalho social. Dessa maneira, o movimento era "[...] ao mesmo tempo conservador e avançado, porque combinava as ideias classistas de um período anterior com as exigências de controle social da nova ordem industrial"7 incorporando as novas demandas que surgiam das classes oprimidas que lutavam contra o trabalho infantil, pela emancipação da mulher e pelo direito à educação obrigatória (PLATT, 1997, p. 25). Como explicita Cury: "[...] os fenômenos não se desenvolvem isoladamente, mas em ligação com outros fenômenos" como parte de uma contradição (1986, p. 31).

Tomou parte desse movimento e contribuiu indiretamente para a disseminação dele na América Latina, o famoso psicólogo e educador norteamericano Granville Stanley Hall (1844-1924), pioneiro no estudo do desenvolvimento da criança, da psicologia genética e da psicologia educacional, tendo sido ele o primeiro americano a ter um $\mathrm{PhD}$ em Psicologia e o primeiro presidente da American Psychological Association (APA). Hall acompanhou de perto o nascente diálogo entre os Estados Unidos e os demais países sobre a construção da ideia de delinquência juvenil e contribuiu para os fundamentos do menorismo, incluíndo os debates na maior parte dos seus dados de pesquisa fartamente utilizados em artigos e livros que sustentavam a tese de adolescência problema.

Alinhado teoricamente com o darwinismo social, Hall criou a child study/estudo da infância como uma nova disciplina científica que buscava estabelecer um nexo entre os estudos científicos da criança e a educação e, em 1904, publicou o livro Adolescence: its psychology and its relations to physiology, anthropology, sociology, sex, crime, religion and education/Adolescência: sua psicologia e suas relações com a fisiologia,

“[...] al mismo tempo conservador y avanzado, porque combinaba las ideas clasistas de un período anterior com la exigencias de control social del nuevo orden industrial”. 
antropologia, sociologia, sexo, crime, religião e educação. O livro contribuiu para a popularização do termo adolescência e, apesar de não ser um termo novo, Hall passou a ser reconhecido como o primeiro que demonstrou uma definição sistemática sobre o assunto.

A perspectiva desenvolvimentista de Hall promoveu intenso alinhamento com as ciências biológicas, medicina, psicologia e, em menor monta, à pedagogia. Portanto, bastante articulado com o movimento de salvadores da infância, culminou por contribuir com as justificativas necessárias para a criação de instituições e Tribunais de Menores, consolidando a tese que a adolescência é uma fase e o adolescente é um problema que precisa ser contido.

\section{A disseminação do movimento menorista}

Entre o final do século XIX e início do século XX surgiram as primeiras leis que tratavam do cuidado com a infância, em vários países. Como exemplo, em 1874, nos EUA, tornou-se famoso o caso de uma menina de nove anos de idade, chamada Mary Ellen McCormack, que teve a tutela retirada de seus pais pelas autoridades judiciárias devido aos abusos físicos que ela sofria.

Para que medidas fossem tomadas foi necessário que a American Society for the Prevention of Cruelty to Animals/ Sociedade Americana para a Prevenção da Crueldade contra Animais, de Nova Iorque, equiparasse a criança aos animais protegidos pela instituição, para que fosse possível uma legitimidade de defesa dos maus tratos que sofria. Esse caso é apresentado, ideologicamente, como o motivo que contribuiu para que fosse criado em Illinoi, Chicago, a Juvenile Court Act/Lei das Cortes Juvenil, no mesmo ano e cidade do Tumulto da Haymarket (1899), já mencionado no corpo do texto. A partir desse evento, os EUA passaram a alardear que possuíam o primeiro tribunal de menores da história (MÉNDEZ, 1998).

Entretanto, o que desvela o aspecto ideológico e a atuação dos Congressos Prisionais é que, nesse mesmo contexto, diversos países realizam movimento semelhante, de maneira coordenada. Assim, a Inglaterra, com a Poor Law Act (1899) para cuidar, explicitamente, de menores abandonados e a Children Act (1908) para prevenir e proteger a infância; a França, com a Lei Roussel (1904), que tratava dos menores abandonados; a Alemanha, em 1900 e, em 1924, com a 
Lei de Assistência à Juventude; a Bélgica, com a Lei de Proteção à Infância (1912) e a Lei que abrange de forma integral o problema dos menores (1919) demonstram que o movimento de proteção à infância foi orientado e articulado nos Congressos Internacionais das Prisões.

Com a criação da Juvenile Court Act/Lei das Cortes Juvenis, nos EUA, disparou-se um movimento que ganhou repercussão na Europa e na América Latina. Na França, por exemplo, o financista Edward Hubert Julhiet8, em 1906, realizou no seu país uma palestra sobre a organização dos tribunais especiais para crianças. A conferência ganhou relevância para a opinião pública francesa quando a revista 'L'Efant' reproduziu a palestra em um livro, fazendo com que o Sétimo Congresso Nacional do Patronato de Freed colocasse a questão na vanguarda do seu programa e a Sociedade Geral das Prisões se interessasse pelo tema (ANNALES, 1931).

Partindo desse crescente interesse, o Museu Social da França enviou Julhiet para estudar as reformas realizadas na Alemanha e Inglaterra e, entre 1907 e 1910, um Comitê de Defesa das Crianças trazidas à justiça discutiu o assunto e proporcionou que o tema fosse pesquisado em teses de doutoramento na área do direito.

Conforme informações do Serviço de Referência Nacional de Justiça Criminal (NCJRS) dos Estados Unidos, dois fatores históricos contribuíram para a evolução dos tribunais de menores, de forma associada, sendo eles: a organização da Conferência Internacional das Prisões, de 1872, já mencionada, e a de 1910. Realizada em Washington nos EUA, a 8. ${ }^{a}$ Conferência foi assistida por delegados de 22 países que se reuniram com os representantes de diversos outros para aprovar a centralização do controle de todas as instituições penais, incluindo as cadeias locais e a inserção dos detentos em atividades laborais - tema ligado ao modelo adotado - sem esquecer, obviamente, a metodologia mais adequada para o atendimento e o tratamento penal dos menores delinquentes.

Essa Conferência teve como principal objetivo anular a distinção entre menores delinquentes, abandonados e maltratados; já que não era possível

$8 \quad$ Engana-se quem pensa que Edward Hubert Julhiet (1870-1931) era magistrado. Engenheiro Civil de Minas, formado pela Escola Politécnica de Paris no ano de 1892, realizou missões de estudos financeiros na América do Sul, América Central, Espanha e EUA. Posteriormente, tornou-se responsável financeiro no Banco da União Parisiense, especializandose no estudo de questões financeiras e contábeis. 
controlá-los e protegê-los, distintamente, resolveram proteger a todos, ou seja, instituicionalizar a todos. A proteção se tornou, assim, o argumento necessário para o controle social e o relatório de conclusão da Conferência Internacional das Prisões, apresentando como primeira resolução: "I. Os jovens delinquentes não devem ser submetidos ao mesmo procedimento penal aplicado aos adultos 9 " (KELSO, 1910, p. 3, tradução do original).

Aderindo ao movimento, a França apresentou, no início de 1910, um projeto elaborado pelo Sr. Ferdinand-Dreyfus à Câmara dos Deputados de Paris. Edward Hubert Julhiet passou a ser considerado o idealizador do sistema de justiça juvenil separado do sistema de justiça dos adultos, sendo, também, presidente da comissão organizadora do Primeiro Congresso Internacional dos Tribunais de Menores, realizado em Paris em 29, em junho de 1911.

O projeto de Lei de Dreyfus possuía a intenção de criar um judiciário diferente do modelo existente. Com isso, seria uma inovação substituir a punição pela reabilitação. Para tanto, os novos juízes deveriam ser defensores morais da sociedade, conforme indicado no Primeiro Congresso que estabeleceu que os juízes necessitavam compreender a alma da criança, ter coração e sensibilidade para o ponto de vista delas (KIMBLE, 2003).

O novo sistema criado na França, em 1912, determinou que as crianças que possuíssem menos de 13 anos de idade não seriam mais vinculadas aos códigos penais e nem submetidas a julgamentos, mas encaminhadas para medidas educativas indicadas por um conselho consultivo civil. Aquelas que tivessem entre 13 e 18 anos de idade seriam julgadas pelo novo sistema de tribunais por um advogado. Assim, no mesmo ano, uma emenda foi acrescentada à Lei, com vistas a tornar as mulheres elegíveis a fim de serem relatoras e realizarem entrevistas com as crianças. Na interpretação do elaborador da emenda, as mulheres possuíam coração, devoção, aptidão e tempo para fazer o trabalho.

\section{Save the Children e a Carta de Genebra}

$9 \quad$ "I. Young delinquents should not be subjected to the penal procedure now applied to adults. 
Em 1918, a I Guerra Mundial terminou com a elaboração do Tratado de Versalhes. O pacto que encerrou a guerra criou a Liga das Nações ${ }^{10} \mathrm{e}$, com ela, algumas agências internacionais que ainda hoje subsistem sob o auspício da sua sucessora, a Organização das Nações Unidas (ONU).

Naquele período, a criança ganhou substancial relevância e as problemáticas associadas à infância foram postas na ordem do dia das agendas políticas. Ainda que os estudos fossem feitos de forma isolada nas áreas médica, psicológica e pedagógica, a entrada da infância nos sistemas produtores de conhecimento não podia deixar de ser, senão, a expressão da sua relevância, já que o tema ganhou notoriedade nos campos médico e psicológico, com o intuito de lograr resultados científicos acerca do desenvolvimento infantil (SOUZA et al., 2017). Assim, quando Ellen Key ${ }^{11}$ disse que o século XX seria o século das crianças é provável que não pudesse imaginar que seria o século das crianças presas! (SANDIN, 1999).

Desde as duas últimas décadas do século anterior houve a organização de um movimento transnacional sob a influência dos EUA, por meio de diversos eventos internacionais, para incentivar a criação de instituições para a proteção da infância. No auge do movimento de salvação da infância, em 1919, a reformadora Eglantyne Jebb fundou uma instituição com um nome bastante apropriado para o período, a Save the Children que, em 2019, completou um século de existência.

A criação da Organização Internacional Não Governamental (OING) Save the Children ocorreu ao final da I Guerra Mundial quando Eglantyne se sensibilizou com o bloqueio realizado pelos vencedores às cidades de Berlim e Viena. Decorrente do fato de que a desnutrição e o raquitismo se tornaram abundante entre as crianças, Eglantyne e sua irmã Dorothy Buxton ingressaram em um movimento referente à causa, denominado Fight the Famine Council/Conselho de Luta Contra a Fome. No movimento foram produzidos panfletos com imagens de crianças, informando que o bloqueio estava

$10 \quad$ "A Liga das Nações é considerada a primeira organização internacional universal e foi criada com o pretenso objetivo de manter a paz mundial, coordenando e controlando os estados soberanos. Após a sua extinção, essas responsabilidades foram absorvidas pela ONU" (ZANELLA, 2014, p. 39).

Ellen Key (1849-1926) foi uma pedagoga russa. A sua obra mais famosa, traduzida para vários idiomas, foi denominada The century of the Child/O século das crianças (190o). 
contribuindo para que milhares delas morressem de fome. As imagens causaram indignação nos transeuntes, o que levou Eglantyne a ser presa (SAVE THE CHILDREN, 2019a; 2019b).

No julgamento, a ativista foi condenada a pagar uma multa de cinco libras. Como ficou impressionado com as imagens, o próprio juiz pagou a multa, que se tornou a primeira doação para a Fundação criada por ela. Depois do ocorrido, as irmãs Jebb decidiram que uma campanha individual não bastava: era necessário criar uma instituição. Assim, em maio de 1919 realizaram uma reunião pública no Royal Albert Hall, em Londres, que culminou com a criação da Save the Children Fund.

Desde o princípio, o Fundo atuou enviando recursos, alimentos e remédios para vários países, tais como, Alemanha, Áustria, França, Bélgica, Hungria, os Bálcãs, para refugiados armênios na Turquia e Rússia. Para tanto, publicava anúncios de página inteira em jornais nacionais e filmagens sobre as condições que as crianças enfrentavam eram exibidas em cinemas por todo o país, causando bastante espanto (STORNIG, 2015). Com os fundos arrecadados, Jebb e seus colegas encheram um navio com 600 toneladas de ajuda com destino à Rússia. Do inverno de 1921 até a maior parte de 1922, as refeições diárias fornecidas pela Save the Children ajudaram a manter 300 mil crianças e mais de 350 mil adultos vivos, por apenas um xelim por pessoa, por semana (SAVE THE CHILDREN, 2019b, p. 2).

Em 26 de setembro de 1924, a Liga das Nações criou um Child Welfare Committee/Comitê de Bem-Estar Infantil, dentro de uma seção social, estabelecendo que os Estados não eram os únicos soberanos em matéria dos direitos da criança: assim, a criança passava a ser uma preocupação internacional, não mais governamental, mas intergovernamental.

Em ato contínuo, a Assembleia Geral (AG) da Liga das Nações adotou a Declaração dos Direitos da Criança, elaborada por Eglantyne Jebb. No ano seguinte, o Comitê iniciou uma agenda em favor da disseminação e criação dos tribunais de menores, em vários lugares do mundo (DROUX, 2010; SAVE THE CHILDREN, 2019a; 2019b). Convém reafirmar que o movimento da Save the Children não foi isolado, como descreve Joëlle Droux (2010), contudo, não há dúvidas de que a atuação do Fundo contribuiu para a sua popularização. 
A Revolução Russa e a ideia de que era necessário educar o homem do socialismo contribuiu para que, do lado oposto, se produzisse a concepção de que era necessário educar o homem do capitalismo. Deste modo, as ações humanitárias tinham um cunho político, econômico, educativo e, como figura central, a criança inocente e educável que precisava ser retirada da sociedade corrompida conforme preconizado, no Emílio de Rousseau (ROUSSEAU, 1995).

Assim, desde o século XIX, os governos, as igrejas, as damas da sociedade, os juízes, os filantropos humanitaristas e o empresariado passaram a prestar mais atenção à educação dos jovens, olhando-os como recurso para o futuro - numa concepção durkheimniana - e, no entre guerras, entenderam o bem-estar infantil como uma pauta importante demais para não ser gerida pelas organizações.

Ao compreender esse movimento, a reformista Jebb e demais militantes do Fundo demonstraram que o ativismo centrado na criança era maior do que o trabalho de assistência local: um trabalho educativo internacional de continuidade para o sistema capitalista. Isso contribuiu para que o trabalho humanitário do Fundo Save the Children promovesse a introdução tutelar e do bem-estar infantil na política internacional. Nessa análise, as políticas estiveram relacionadas ao Welfare State/estado de bem-estar social europeu, enquanto na América Latina vinculou-se ao assistencialismo e à concepção tutelar menorista de infância dos mais pobres. Não foi uma coincidência que a Liga das Nações tenha criado o Child Welfare Committee/Comitê de Bem-Estar Infantil utilizando o termo bem-estar.

\section{A Declaração dos Direitos da Criança de 1924}

Durante a I Guerra Mundial, a ativista britânica Eglantyne Jebb atuou em algumas organizações que deram início a um movimento de defesa dos direitos da criança. A partir dessa iniciativa, em 1919 estruturou-se a OING Save the Children Fund International Union/Fundo da União Internacional para a Salvação da Infância ${ }^{12}$. Em 23 de fevereiro de 1923, a OING redigiu uma carta em

\footnotetext{
12 A Save the Children, apesar de não ter sido criada como uma organização permanente, ainda se encontra ativa. Talvez, por isso, apareça em documentos com diferentes nomenclaturas. $\mathrm{Na}$ tradução do livro de Korczak, O direito da criança ao respeito, escrito em 1915, a OING aparece como União Internacional de Ajuda à Criança. Nos países de língua inglesa, a Organização
} 
defesa das crianças, que foi ratificada em 26 de setembro de 1924 por ocasião da $5^{5^{a}}$ sessão da Liga das Nações, como a Declaração dos Direitos da Criança, também denominada Declaração de Genebra (HUMANIUM, s.p.).

Assim, apesar da adoção da Declaração ser considerada, por muitos, como um evento importante na história do humanitarismo e direitos humanos - pois implicou que as crianças, pela primeira vez, ganhassem a atenção dos mais altos círculos da política internacional, tendo como foco a ideia de salvação da criança - a perspectiva liberacionista defendia a liberdade e um protagonismo da criança, enquanto indivíduo, acima de tudo, o que contrariava a ideia de uma criança indefesa e que precisava ser protegida porque não possuía voz. Essa perspectiva liberacionista irá figurar, em alguma medida, na Convenção dos Direitos da Criança, promulgada 30 anos depois.

A Declaração não surtiu o efeito almejado em decorrência do panorama histórico porque "[...] não foi o resultado de profundos e acalorados debates filosóficos acerca da natureza e das necessidades das crianças. Sua origem, aliás, pode ser vista quase que como incidental: partiu de um gesto humanitário praticado em resposta aos horrores da guerra" (BARBOSA, 2008, p. 25-26). Para a pesquisadora, a Declaração surgiu na forma de "[...] manifesto particular elaborado no calor da indignação contra o abandono das crianças no pós-guerra e, movida por essa mesma indignação, é abraçada inconteste pela comunidade internacional". Portanto, não surtiu efeito, dentre outras coisas, porque "[...] o documento não é fruto da reflexão acerca de o que é a criança, mas uma tentativa de resposta sobre o que se deve fazer com ela" (BARBOSA, 2008, p. 26).

Nesse aspecto, discordamos dos autores por considerarmos que à Declaração atribuiu-se o ensejo das organizações, dos estados, governos e políticas do período. Assim, ela não fracassou no seu intuito: ao contrário, foi um completo sucesso, já que contribuiu para a separação de crianças e adultos no cumprimento da pena, para a instauração do menorismo com a premissa tutelar e do bem-estar social para justificar a institucionalização dos menores - filhos da classe trabalhadora - como algo necessário naquele período de embate entre capitalismo e socialismo.

aparece com a nomenclatura Save the Children; na Suécia, como Rädda Barnen International; na França Union International de Secours a l'Enfant (UISE) (JANUSZEWSKA; VALEEVA, 2016). 
Ocorre que o atendimento caritativo dado à criança se diferencia do atendimento filantrópico, ainda que não seja estanque a passagem de um para outro. Conceitualmente, o modelo filantrópico utiliza explicações científicas de base higienistas e sanitaristas para fundamentar o tratamento destinado às crianças. Por exemplo, para tratar da criança pobre, a Declaração de 1924 utilizou termos mais comuns como, tais como, atrasada, órfãs e delinquentes; enquanto, na Carta de 1959, a mesma criança se tornou incapacitada física, mental ou socialmente, merecendo cuidados especiais por sua condição peculiar ${ }^{13}$ (ZANELLA, 2014).

\section{O menorismo na América Latina e no Brasil}

O embate entre socialismo e capitalismo, sob a polarização internacional do final do século XIX, foi um fator histórico determinante que contribuiu para substituir o modelo retribucionista de penalização de crianças pelo modelo tutelar. A separação de adultos e menores na execução da pena; a criação da Juvenile Court Act/Lei das Cortes Juvenis; a consequente eliminação das formalidades judiciais para os menores com vistas a sua proteção; a diferenciação entre as instituições de correção e reformatórios produzidas nos Congressos Internacionais das Prisões; a eliminação da distinção entre infração e abandono no âmbito da justiça; a fundamentação da adolescência problema do psicologista Stanley Hall; a promulgação da Declaração dos Direitos da Criança - Carta de Genebra de 1924 - foram fatores desencadeados no processo de construção do menorismo, mas ainda faltava um fator primordial.

O grupo de reformistas da virada do século, formado por filantropos e juristas, precisavam responder um problema: como institucionalizar crianças que cometeram crimes com discernimento, sem discernimento ou que precisavam ser protegidas para prevenir a delinquência? Na visão dos reformistas, a resposta para o problema tinha uma causa comum, os pais e, em alguma medida a sociedade corrompida, para utilizar os termos de Rousseau. Para resolver essa questão, era necessário intervir e substituir os pais

13 Essa mudança de subsídio não foi abrupta, mas o tema é mais bem desenvolvido no artigo intitulado A Declaração dos Direitos da Criança de 1959, o Unicef, a Base teórica de Janusz Korczak e Phillipe Ariés: princípios liberais da criança protagonista, ainda no prelo. 
negligentes ${ }^{14}$ : foi assim que teve início a substituição da tutela dos pais pela tutela do Estado, com o princípio de parens patriae/pai da pátria, que se refere ao poder de política pública do Estado de intervir contra um pai ou guardião legal e retirando o pátria potestas/pátrio poder dos genitores.

O termo menor, a partir de então, deixou de ser utilizado para marcar a diferença em relação à idade do adulto, ou uma contraposição matemática de maior e menor, passando a significar um conceito que segregava e diferenciava as crianças e os adolescentes como pertencentes a dada condição social e a um modelo de família nuclear burguês. Deste modo, o menor se tornou caracterizado como a criança pobre, pertencente às famílias que também foram estigmatizadas como desestruturadas, porque não obedeciam ao modelo estabelecido pela burguesia (ZANELLA, 2018).

Méndez (2006) marca o período entre 1919, ano de publicação da Lei Agote na Argentina e 1989, ano de promulgação da Convenção dos Direitos da Criança, como marcos da vigência do modelo tutelar na América Latina. Entretanto, apesar de, formalmente, a Lei de 1919 ser um marco jurídico, a influência do menorismo já pode ser identificada no Brasil, em 1875. Nesse ano, o Decreto n. ${ }^{\circ}$ 5.849, que normatizou o Regulamento ao Asylo de Meninos Desvalidos, mencionou "Os menores do Asylo, serão entregues a seus pais, ou, sendo orphãos, postos á disposição de algum dos respectivos Juizes, salvo o caso em que se julgue conveniente dar-lhes outro destino (BRASIL, 1875, art. $6^{\circ}$ ). Essa única menção já apontava na direção do que viria a se realizar nos próximos anos.

\begin{tabular}{|c|c|c|}
\hline TERIMO & DECRETO No $5.849 / 1875$ & DECRETO No $8.910 / 1883$ \\
\hline Meninos & Art. $1^{\circ}$ e $17, \S 6^{\circ}$ & Art. $3^{0}$ \\
\hline Asylados & 14 vezes & 14 vezes \\
\hline $\begin{array}{l}\text { Meninos } \\
\text { desvalidos }\end{array}$ & $\begin{array}{c}\text { Preâmbulo (3 vezes), Art. } 2^{\circ}, \\
\text { Disposição transitória ( } 2 \\
\text { vezes) }\end{array}$ & $\begin{array}{l}\text { Preâmbulo (3 vezes), Art. } 1^{0}, \text { Art. } 7^{0} \\
\text { Disposição transitória ( } 2 \text { vezes) }\end{array}$ \\
\hline Órphãos & Art. $6^{\circ}$ & Art. $4^{\circ}, \S 1^{\circ}$ e $\S 2^{\circ}$ \\
\hline
\end{tabular}

14 No século XIX, “[...] a grande indústria dissolveu, juntamente com a base econômica do antigo sistema familiar [...] as próprias relações familiares antigas", sendo, portanto, “[...] necessário proclamar os direitos das crianças”, posto que, elas precisavam de “[...] mais proteção contra seus pais do que contra qualquer outra pessoa. [...]. Os pais não deveriam deter o poder absoluto de transformar seus filhos em simples máquinas com o objetivo de extrair deles certa quantia de salário semanal" (MARX, 2013, p. 559). "Os pais degradados, só pensam em arrancar o máximo possível de seus filhos. Estes, por sua vez, quando crescidos, não dão mais a mínima para seus pais e os abandonam" (MARX, 2013, p. 540). "Nada mais natural do que a enorme ocorrência de alcoolismo, já desde a infância, nessa classe inteira” (MARX, 2013, p. 536). 
Revista Brasileira de História \& Ciências Sociais - RBHCS

Vol. 13 No 25, Edição Especial de 2021

Menor/Menores

Alumnos

FONTE: Dados da pesquisa, 2020.

NOTA $^{1}$ : Brasil (1875) e (1883).
Art. $5^{\circ}$ (3 vezes) Art. $37 \S 1^{\circ}$ 15 vezes

Como podemos observar na comparação entre os dois decretos, a quantidade de vezes que a palavra asylados apareceu não foi alterada, sendo referenciada 14 vezes, em ambos os decretos. Na análise podemos perceber que tanto as palavras meninos quanto a palavra alumnos perderam quantidade de menções na Lei de 1883. Ou seja, no Decreto de 1890, os termos alumnos e meninos foram substituídos por órphãos e menores, que aparecem quatro vezes.

Outra diferenciação que a comparação evidencia é que o Decreto de 1890 menciona, pela primeira vez, a aceitação em atender menores filhos de pais vivos. Assim, a menção à palavra órfão do primeiro decreto foi utilizada para dizer que os “menores serão entregues a seus pais, ou, sendo orphãos, postos á disposição de algum dos respectivos Juizes, salvo o caso em que se julgue conveniente darlhes outro destino" (BRASIL, 1875, art. 6º grifo nosso).

No último decreto analisado, entretanto, essa menção é mais impositiva ao estabelecer que: "Serão admittidos no Asylo: $1^{\circ}$ Os que forem orphãos de pai e mãi; $2^{\circ}$ Os que forem orphãos de pai; $3^{\circ}$ Os que, com pai e mãi, não puderem ser por elles mantidos ou educados” (BRASIL, 1883, art. $4^{\circ}$, grifos nossos). Definiu ainda que: “As condições de admissão serão provadas: sendo orphão o menor, com attestados de completa indigencia e de absoluta falta de amparo, passados pelo Vigario da freguezia em que residir o dito menor e pelo Juiz respectivo, e com certidões de idade e de obito dos pais, ou documentos equivalentes a essas certidões; não sendo orphão o menor, por analogos attestados passados pelo Vigario e Subdelegado da respectiva freguesia" (BRASIL, 1883, art. $4^{\circ}$, grifos nossos).

Apesar dessa alteração efetiva nas terminologias, nesse período não havia ainda uma apropriação cultural do termo, o que pode ser vislumbrado no fato de que o Código Penal de 1890 seguiu a mesma terminologia do Código Criminal de 1830 que, por sua vez, utilizava a palavra menor numa alusão matemática ao termo menos de. A exemplo: "Não são criminosos: $\S 1^{\circ}$ Os menores de 9 annos completos; $\S 2^{\circ}$ Os maiores de 9 e menores de 14, que obrarem sem discernimento; [...]" (BRASIL, 1883, art. 27). 
De maneira geral, as publicações da área da infância estabelecem as legislações publicadas a partir da segunda década do século XX como precursoras de um novo modelo de atendimento para a infância. Entretanto, em 1890, o Chefe do Governo Provisório, Deodoro da Fonseca, publicou o decreto n. ${ }^{0} 439$ que antecipou em duas décadas 15 essa proposta ao estabelecer "[...] as bases para a organização da assistencia á infancia desvalida” (sic!) (BRASIL, 1890, p. 1). O Quadro abaixo evidencia os termos indicados no Decreto.

QUADRO 2 - A INFÂNCIA DESVALIDA NO DECRETO No 439 (1890)

\begin{tabular}{|c|c|c|}
\hline ESPECIFICIDADE & & ARTIGOS E INCISOS \\
\hline $\begin{array}{l}\text { Instituições de } \\
\text { asilo e } \\
\text { recolhimento }\end{array}$ & Art. $1^{\circ}$ & $\begin{array}{l}\text { A assistencia á infancia desvalida na Capital Federal, por parte } \\
\text { dos poderes publicos, será constituida emquanto o Governo } \\
\text { não puder fundar outros estabelecimentos, pelas actuaes } \\
\text { instituições - Casa de S[ão] José e Asylo de Meninos } \\
\text { Desvalidos, destinadas a receber, manter e educar menores } \\
\text { desvalidos, do sexo masculino, desde a idade de } 6 \text { annos até } \\
\text { aos } 21 . \\
\text { Os dous estabelecimentos se completarão mutuamente, sendo } \\
\text { recebidos: na Casa de S[ão] José os menores de } 6 \text { annos até } \\
\text { 12, e no Asylo de Meninos Desvalidos os dessa idade [12] até } \\
\text { 14 annos. }\end{array}$ \\
\hline $\begin{array}{c}\text { Considerados } \\
\text { desvalidos }\end{array}$ & $\begin{array}{l}2^{\mathrm{o}} \\
3^{\mathrm{o}} \\
4^{\mathrm{o}}\end{array}$ & $\begin{array}{l}\text { São considerados desvalidos, para o fim da admissão nos } \\
\text { ditos estabelecimentos, os menores, comprehendidos nas } \\
\text { idades apontadas, que não tiverem pessoa alguma que os deva } \\
\text { e possa manter convenientemente, a saber: } \\
\text { Os abandonados na via publica e que, recolhidos aos ditos } \\
\text { estabelecimentos, mediante requisição do chefe de policia ou } \\
\text { do juiz de orphãos, não forem reclamados pelos paes, tutores } \\
\text { ou protectores em condições de prover á sua manutenção, } \\
\text { dentro de } 15 \text { dias, à vista de annuncio feito pelo respectivo } \\
\text { director nos jornaes de maior circulação, durante aquelle } \\
\text { prazo; } \\
\text { Os orphãos de pae e mãe, quando a indigencia destes seja } \\
\text { provada; } \\
\text { Os orphãos de pae, sob a mesma condição; } \\
\text { Os que, tendo pae e mãe, não puderem ser por estes } \\
\text { mantidos e educados physica ou moralmente, dando-se } \\
\text { o desamparo forçado. }\end{array}$ \\
\hline
\end{tabular}

FONTE: Dados da pesquisa, 2020.

NOTA $^{1}$ : Adaptado (BRASIL, 1890).

Em 1904, Mario Franco Vaz ,Secretário e depois Diretor da Escola Correcional Quinze de Novembro, atendeu à solicitação do Ministro da Justiça e dos Negócios do Brasil para, num prazo de seis meses, elaborar um trabalho sobre os delinquentes juvenis. Em 1905, entregou ao ministro o trabalho intitulado $A$ infância abandonada.

15 Trata-se do Decreto-Lei n. ${ }^{\circ}$ 16.272/1923 que aprovou o regulamento da assistência e proteção aos menores abandonados e delinquentes (BRASIL, 1923). 
Consciente da importância da educação e embasando-se na obra de Herbert Spencer, de 1861, Educação Intellectual, moral e physica ${ }^{16}$, Vaz concluiu que ninguém alimentava dúvidas da nefasta influência sobre os próprios filhos, exercida "[...] pelos paes vagabundos, ébrios, desordeiros, jogadores, ladrões, criminosos, caftens, barbaros, vivendo de expedientes deshonestos, arrastando uma vida de dissolução e de vicios" (sic!) (VAZ, 1905, p. A-G-113).

Para enfatizar a proposta de retirada do pátrio poder, Vaz (1905) relacionou uma lista de países que já realizavam tal feito e que haviam atualizado a legislação para diminuir o pátrio poder e, consequentemente, aumentar o poder do Estado sobre os filhos dos pobres: Noruega, Dinamarca, Bélgica, Suíça, Prússia, Áustria, Hungria, Portugal, Itália, Inglaterra e França, alguns dos países citados como exemplos. Para apresentar tal proposição, Vaz subsidiou-se nos debates realizados nos Congressos Penitenciários Internacionais de 1885 e 1890.

Apesar do pátrio poder ser um direito consuetudinário desde a Roma Antiga, no VI Congresso Internacional das Prisões ocorrido em Roma (1885), os congressistas consideraram esse o meio mais seguro de se evitar o desleixo dos pais que deveriam ter sua autoridade suprimida. Assim, o Congresso seguinte realizado em São Petesburgo, em 1890, reconheceu o direito do Estado que, em circunstâncias consideradas imperiosas, deveria decretar a perda do poder paterno, o que aconteceria sempre que algo comprometesse a situação moral ou material da criança. É desnecessário dizer que essa lógica só teve validade para as crianças filhas das denominadas classes perigosas. Apesar dessa proposição e, de alguma maneira, o Estado realizar isso de maneira ocasional, demorou alguns anos para isso viesse a vigorar na Lei, o que só aconteceu na segunda década do século XX.

\section{Considerações Finais}

$\mathrm{O}$ artigo descreve o processo de estruturação do modelo tutelar que teve início entre meados do século XIX e se consolidou no início do século XIX, resultado da criação da Juvenile Court Act/Lei das Cortes Juvenis, em Chicago,

16 SPENCER, Herbert. Educação Intellectual, moral e physica. Porto: Alcino Aranha \& Companhia. 1888. 
em 1889, e do empenho dos reformadores que ficaram conhecidos como Child Savers/Salvadores da infancia, dentre eles, Stanley Hall. Neste sentido, a preocupação salvacionista dos abandonados e delinquentes culminou com os debates nos Congressos Internacionais Penitenciários que, de lá, se disseminaram para o mundo.

No mesmo contexto, a reformista Eglantyne Jebb fundou na Europa, em 1919, a Save the Children, uma OING que possui forte atuação, ainda nos dias de hoje. Essa fundação que leva no nome a preocupação em salvar as crianças elaborou o primeiro documento histórico que proclamou direitos específicos para as crianças, a Declaração dos Direitos da Criança de 1924 ou Declaração de Genebra.

O estudo conclui que o modelo tutelar nasceu no contexto de embate entre socialismo e capitalismo, sendo essa polarização internacional do final do século XIX, um fator histórico determinante que contribuiu para substituir o modelo retribucionista de penalização de crianças pelo modelo tutelar. Assim, no contexto entre o século XIX e início do século XX, o modelo tutelar pode ser conceituado como uma política de contenção dos filhos da classe trabalhadora, que articulou a separação de adultos e menores na execução da pena. Para tanto, a partir de 1899 criou tribunais juvenis e elaborou um documento formal intitulado Declaração dos Direitos da Criança, em 1924. Apesar de ter eliminado as formalidades judiciais para os menores com vistas a sua suposta proteção, o modelo tutelar estabeleceu uma diferenciação entre instituições de correção e de reforma eliminando, também, a distinção entre infração e abandono no âmbito da justiça. Além disso, o menorismo sustentou-se na psicologia do desenvolvimento e na concepção de que a adolescência é uma fase permeada por crises, sendo Stanley Hall um dos seus maiores expoentes. Juridicamente, a proposta menorista possui um segundo pilar, a retirada do pátria potestas/pátrio poder das famílias consideradas inadequadas por serem, em sua totalidade, pobres. Além disso, promoveu a ampliação da inimputabilidade penal para 18 anos com vistas a garantir que sua política de proteção tivesse um maior alcance, mas esse é assunto para o próximo artigo. 


\section{REFERÊNCIAS}

ANNALES. Edward Hubert Julhiet (1870-1931). Disponível em: <http://annales.org/archives/x/julhiet.html>. Acesso em 06/mai./2012. (1931).

BARBOSA, Joana Bezerra Cavalcanti. Influência e aplicabilidade das normas de direito internacional na realidade dos jovens em conflito com a lei. (Dissertação, Direito). Brasília, DF: Centro Universitário de Brasília, 2008. Disponível em:

<http://www.dominiopublico.gov.br/download/teste/arqs/cp073021.pdf >. Acesso em: 14 jun. 2019. (2008).

BECCARIA, Cesare. Dos delitos e das penas. 1764. 2. ed. 6. reimp. Trad. Torrieri Guimarães. São Paulo: Martin Claret, 2000. (A obra-prima de cada autor).

BRASIL. Decreto no 16.272, de 20 de dezembro de 1923: Approva o regulamento da assistencia e proteção aos menores abandonados e delinquentes. Disponível em: <http://www2.camara.leg.br/legin/fed/decret/1920-1929/decreto-16272-20dezembro-1923-517646-publicacaooriginal-1-pe.html>. Acesso em: 8 ago. 2016. (1923a).

BRASIL. Decreto no 439, de 31 de Maio de 1890: estabelece as bases para a organização da assistencia á infancia desvalida. Acesso em: 17 jan. 2018. Disponível em: <http://www2.camara.leg.br/legin/fed/decret/18241899/decreto-439-31-maio-1890-503049-publicacaooriginal-1-pe.html>. (1890).

BRASIL. Decreto no 8.910, de 17 de março de 1883: Dá novo Regulamento ao Asylo de Meninos Desvalidos. Acesso em: 31 ago. 2017. Disponível em: <http://www2.camara.leg.br/legin/fed/decret/18241899/decreto-8910-17-marco-1883-544329-publicacaooriginal-55394pe.html>. (1883).

BRASIL. Decreto no 5.849, de 9 de janeiro de 1875: approva o Regulamento do Asylo de meninos desvalidos. Acesso em: 23 ago. 2017. Disponível em: <http://www2.camara.leg.br/legin/fed/decret/18241899/decreto-5849-9-janeiro-1875-549781-publicacaooriginal-65299-pe.html>. (1875).

CARPENTER, Mary. Juvenile delinquents: their condition and treatment. London: University of Oxford, 1853. Acesso em: 06 fev. 2018. Disponível em: $<$ https://archive.org/stream/juveniledelinquoocarpgoog\#page/n9/mode/1up> . (1853).

CARPENTER, Mary. Reformatory Schools for the children of the perishing and dangerous classes and for juvenile offenders. London: Harvard College, 1851. Acesso em: 06 fev. 2018. Disponível em: $<$ https://archive.org/details/reformatoryschooocarpgoog >. (1851). 
CIP. Congresso Internacional das Prisões. Bulletin de la société générale des prisons. A. 24. Paris: Marchal et Billard, 1900. (1900).

CIP. Congrès Pénitentiaire International. GUILLAUME, Louis. Le Congrès pénitentiaire international de Stockholm. 15-26 août 1878: publiés sous la direction de la Commission pénitentiaire internationale par le Guillaume. Stockholm, Sweden, 1879. (1879).

CIP. Congresso Internacional das Prisões. Congresso Internacional sobre a Prevenção e Repressão do Crime: incluindo o tratamento penal e reformatório: relatório preliminar do comissário nomeado pelo Presidente para representar os Estados Unidos no Congresso em cumprimento de uma resolução conjunta de 7 de março de 1871. Washington: Government Printing Office, 1872. (1872).

CURY, Carlos Roberto Jamil. Educação e contradição: elementos metodológicos para uma teoria crítica do fenômeno educativo. São Paulo: Cortez, Editores Associados, 1986. (1986).

DROUX, Joëlle. Un enjeu sans frontière? Stratégies et rôle des réseaux transnationaux dans la diffusion du modèle des tribunaux pour mineurs en Europe (1900-1940). (2010). Disponível em: $<$ http://triangle.ens-lyon.fr/ >. Acesso em: 10 jun. 2019. (2010).

DURKHEIM, Émile. Educação e sociologia. Trad. Stephania Matousek. Petrópolis, RJ: Vozes, 2011. (Textos fundantes da educação). (2011).

HUMANIUM. Declaración de Ginebra sobre los Derechos del Niño, 1924. Disponível em: <https://www.humanium.org/es/ginebra-1924/>. Acesso em: 14 jun. 2019. (s/d).

JANUSZEWSKA, Edyta; VALEEVA, Roza A. Children's rights in Poland and Russia in the context of Janusz Korczak's in heritage. Intenational Journal of Environmental \& Science Education, 11(3), 327-338. Disponível em: <http://www.ijese.net/makale/142>. Acesso em: 14 jun. 2019. (2016).

KELSO, J. J. Conclusions of the International Prison Congress held in Washington, Oct. 2-8, 1910: Digitized by the Internet Archive in 2010 with funding from University of Toronto, 1910. (1910).

KIMBLE, Sara L. For the family, France, and humanity: authority and maternity in the Tribunaux pour Enfants. In: Proceedings of the Western Society for French History, vol. 31, 2003. (2003).

LOMBROSO, Césare. O homem delinqüente. 1. reimp. Trad. Sebastião José Roque. São Paulo: Ícone, 2001. (Fundamentos de direito). (2001).

MARKEL, Howard. Case Shined First Light on Abuse of Children. The New York Times. Acesso em: 29 jul. 2020. Publicado em: 14 dez. 2009. Disponível em: https://www.nytimes.com/2009/12/15/health/15abus.html?ref=science. (2009).

MARX, Karl. O capital: crítica da economía política: Livro I: o proceso de produção do capital. Trad. Rubens Enderle. São Paulo: Boitempo, 2013 (MarxEngels). (2013).

MÉNDEZ, Emilio García. Adolescentes e responsabilidade penal: um debate 
latino americano. In: Justiça para o século 21: instituindo práticas restaurativas. Disponível em:

http://justica21.web1119.kinghost.net/arquivos/bib_206.pdf. Acesso em 25 ago. 2020. (2006).

MÉNDEZ, Emílio García. Infância e cidadania na América Latina. São Paulo: Hucitec/Instituto Ayrton Senna, 1998. (1998).

PLATT, Antony M. Los “salvadores del niño": la invención de la delincuencia. 3. ed. México: siglo veintino, 1997. (1997).

ROUSSEAU, Jean-Jacques. Emílio ou da Educação. Trad. Sérgio Milliet. Rio de Janeiro: Bertrand Brasil, 1995. (1995).

SANDIN, Bengt. Imagens em conflito: Infâncias em Mudança e o Estado de Bem-Estar Social na Suécia. Reflexões sobre O Século da Criança. Revista Brasileira de História, São Paulo, vol. 19, n.37, Set. 1999. Acesso em 22 jun. 2015. Disponível em http://www.scielo.br/scielo.php?script=sci_arttext\&pid =So102-01881999000100002. (1999).

SAVAGE, Jon. A criação da juventude: como o conceito de teenage revolucionou o século XX. Trad. Talita M. Rodrigues. Rio de Janeiro: Rocco, 2009. (2009).

SAVE the Children. Our founder Eglantyne Jebb: the woman who started save the children. (2019). Disponível em: <https://www.savethechildren.org/us/about-us/why-save-thechildren/eglantyne-jebb>. Acesso em: 10 jun. 2019. (2019a).

SAVE the Children. Our history. (2019). Acesso em: 10 jun. 2019. Disponível em: <https://www.savethechildren.org.uk/about-us/our-history>. (2019b).

SOUZA, Jhaína Aryce de Pontes; et. al. Ressignificando os conceitos de criança e infância. In: Revista Amazônida, 2017, a.2, n.3, pp. 113-129. Disponível em: <http://www.periodicos.ufam.edu.br/amazonida/article/view/4116/359>. Acesso em: 11 jun. 2019. (2017).

STORNIG, Katharina. 'Geneva, 1924: the Geneva Declaration of the Rights of the Child'. In: Online Atlas on the History of Humanitarianism and Human Rights. Disponível em: <http://hhr-atlas.ieg-mainz.de/articles/storniggeneva>. Acesso em: 14 jun. 2019. (2015).

VAZ, Mario Franco. A infância abandonada. MJNI. Ministério da Justiça e dos Negócios Interiores. Relatório I dos anos de 1904 e 1905 apresentado ao Presidente da Republica dos Estados Unidos do Brasil pelo Ministro José Joaquim Seabra. Anexo G, I-215, p. 942-1184. (1905).

ZANELLA, Maria Nilvane. A perspectiva da ONU sobre o menor, o infrator, o delinquente e o adolescente em conflito com a lei: as políticas de socioeducação (Dissertação, Educação). Maringá, PR: UEM, 2014. 269f. Disponível em: <http://www.ppe.uem.br/dissertacoes/2014\%20\%20Maria\%20Nilvane.pdf $>$. (2014).

ZANELLA, Maria Nilvane. Da institucionalização de menores à desinstitucionalização de crianças e adolescentes: os fundamentos ideológicos da extinção da FUNABEM como solução neoliberal. (Tese, Educação). 
Revista Brasileira de História \& Ciências Sociais - RBHCS

Vol. $13 \mathrm{~N}^{\circ}$ 25, Edição Especial de 2021

Maringá: Universidade Estadual de Maringá, 2018. 586 f. Disponível em:

<http://www.ppe.uem.br/teses/2018/2018\%20-\%20Maria\%20Nilvane.pdf>. (2018).

Recebido em Agosto de 2020

Aprovado em Dezembro de 2020

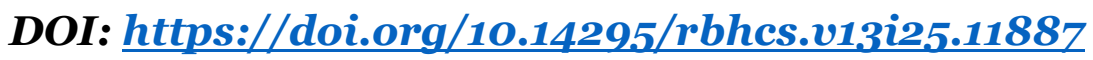

